\title{
Estimate of the atmospheric turbidity from three broad-band solar radiation algorithms. A comparative study
}

\author{
G. López and F. J. Batlles \\ Departamento de Ingeniería Eléctrica y Térmica, EPS La Rábida, Universidad de Huelva, Ctra. Palos de la Frontera s/n., \\ 21819 Huelva, Spain
}

Received: 5 December 2003 - Revised: 26 February 2004 - Accepted: 30 March 2004 - Published: 7 September 2004

\begin{abstract}
Atmospheric turbidity is an important parameter for assessing the air pollution in local areas, as well as being the main parameter controlling the attenuation of solar radiation reaching the Earth's surface under cloudless sky conditions. Among the different turbidity indices, the Ångström turbidity coefficient $\beta$ is frequently used. In this work, we analyse the performance of three methods based on broadband solar irradiance measurements in the estimation of $\beta$. The evaluation of the performance of the models was undertaken by graphical and statistical (root mean square errors and mean bias errors) means. The data sets used in this study comprise measurements of broad-band solar irradiance obtained at eight radiometric stations and aerosol optical thickness measurements obtained at one co-located radiometric station. Since all three methods require estimates of precipitable water content, three common methods for calculating atmospheric precipitable water content from surface air temperature and relative humidity are evaluated. Results show that these methods exhibit significant differences for low values of precipitable water. The effect of these differences in precipitable water estimates on turbidity algorithms is discussed. Differences in hourly turbidity estimates are later examined. The effects of random errors in pyranometer measurements and cloud interferences on the performance of the models are also presented. Examination of the annual cycle of monthly mean values of $\beta$ for each location has shown that all three turbidity algorithms are suitable for analysing long-term trends and seasonal patterns.
\end{abstract}

Key words. Atmospheric composition (aerosols and particles; transmission and scattering of radiation) - Meteorology and atmospheric dynamics (radiative processes)

\section{Introduction}

Atmospheric turbidity is associated with atmospheric aerosol load. Aerosols are solid and liquid particles suspended in the atmosphere, ranging in size from $10^{-3} \mu \mathrm{m}$ to several tens

Correspondence to: G. López

(gabriel.lopez@die.uhu.es) of microns. These particles are either of natural sources (such as volcanic eruptions, dust storms, forest and grassland fires, sea spray, etc.) or of anthropogenic origin (such as the burning of fossil fuels). An increase in the concentration of aerosols in some urban regions caused by human activity has a significant impact on the environmental quality of the cities, which makes the air turbid with lower visibility, the atmospheric opto-chemistry faster, and the air polluted. In addition, aerosols play an important role in absorption and scattering of solar radiation, as well as in the physics of clouds and precipitation. Therefore, atmospheric turbidity is not only an important factor for monitoring the air pollution, but also in meteorology, climatology and for designing of solar energy systems.

Due to the relationship existing between aerosols and attenuation of solar radiation reaching the Earth's surface, different turbidity factors based on radiometric methods have been defined to evaluate the atmospheric turbidity. Some of these are the Linke turbidity factor, $T_{L}$ (Linke, 1922), the Ångström turbidity parameters, $\alpha$ and $\beta$ (Ångström, 1929), the Shüepp coefficient, $B$ (Shüepp, 1949), the UnsworthMonteith turbidity factor, $T_{U}$ (Unsworth and Monteith, 1972) and the horizontal visibility. Among them, Angström turbidity parameters are commonly used. They were defined by Ångström (1929) through the relation

$\tau_{a}(\lambda)=\beta \lambda^{-\alpha}$,

where $\tau_{a}(\lambda)$ is the aerosol optical thickness at wavelength $\lambda(\mu \mathrm{m})$. The turbidity coefficient $\beta$ (defined at $1 \mu \mathrm{m}$ ) is related to the aerosols content, whereas the wavelength exponent $\alpha$ is related to the size distribution of particles. Turbidity coefficient $\beta$ typically ranges from 0.02 , for low aerosol load, to 0.5 , for high aerosol load. On the other hand, large values of $\alpha(\sim 4)$ indicate a relatively high ratio of small particles to large particles. There are different techniques to estimate $\alpha$ and $\beta$ from measurements of direct solar spectral irradiance (Cachorro et al., 1987). In this regard, a significant effort is being conducted to establish a world-wide ground-based aerosol monitoring network under the framework of the Aerosol Robotic Network (AERONET, Holben 
et al., 1998). However, these spectral measurements have only recently been established and the sparseness of this data both spatially and temporally makes it impossible to study current long-term turbidity trends. To circumvent this limitation, several methods based on broad-band measurements of solar radiation and related atmospheric parameters can be used in the first place (Louche et al., 1987; Pinazo et al., 1995; Gueymard and Vignola, 1998; Power, 2001). These methods estimate the turbidity coefficient $\beta$ and assume a constant value for the wavelength exponent $\alpha$, which is often set to 1.3 , following the reference value originally proposed by Ångström for continental aerosols. This assumption is needed due to the unavailability of measurements of the wavelength exponent.

In this work, three methods for estimating the turbidity coefficient $\beta$ from broad-band solar radiation data are compared. They were formulated by Dogniaux (1974), Louche et al. (1987) and Gueymard and Vignola (1998), respectively. The first two were selected because of their simplicity and extensive use in order to either estimate solar radiation components from parametric models or to study seasonal turbidity variations (Sinha et al., 1998; Pedrós et al., 1999; Batlles et al., 2000; Li and Lam, 2002; Janjai et al., 2003), whereas the third one is new. It is important to note that these turbidity algorithms need knowledge of total precipitable water in the atmosphere, in order to take into account the depletion of incident solar radiation due to this component. This information may be obtained from radiosonde soundings or from measurements of spectral solar radiation in water vapor absorption bands. However, these measurements are often unavailable at a specific site. For this reason, alternative methods have been proposed to estimate precipitable water content from surface conditions using correlations with parameters such as dew point temperature or using equations based on temperature and relative humidity (Iqbal, 1983). These correlations are possible because atmospheric water vapor is strongly concentrated in the lower atmospheric layers (Viswanadham, 1981). Among the existing formulas, Leckner's approach (Leckner, 1978) and the Reitan based formula reported by Wright et al. (1989) are widely employed. More recently, Gueymard (1994) has reported a new approach to calculate precipitable water based on the relationship between the water vapor scale height and temperature. In general, each of these approaches provides different precipitable water values, which can lead to over/under estimation of turbidity levels. For this reason, in Sect. 4 a study is initially carried out to analyse the differences on precipitable water calculated by means of several methods and how the selected turbidity algorithms are affected by these differences. In Sect. 5, turbidity estimates by each selected algorithm are first compared with each other. Next, broad-band turbidity estimates are compared with experimental values derived from sunphotometric measurements. Lastly, the annual cycle of monthly mean values of the coefficient $\beta$ calculated by each turbidity algorithm is examined in climatologically diverse regions.

\section{Experimental Data}

\subsection{Broadband solar irradiance measurements}

In order to estimate the turbidity coefficient by means of broad-band algorithms, data collected at eight radiometric stations were used. Table 1 summarises their geographical locations, the number of hours and the recording period. The stations were chosen with the intention of best representing a wide diversity of climates. In this sense, Almería's station is located on a seashore site on the Mediterranean coast of southeastern Spain. High frequency of cloudless days, an average annual temperature of $17^{\circ} \mathrm{C}$, and the persistence of high humidity characterise the local climate. Granada's station is located on the outskirts of Granada (southeastern Spain). Cool winters and hot summers characterise this inland location. The U.S. stations are part of NOAA's Surface Radiation budget network - SURFRAD - (Augustine et al., 2000). They represent inland locations with different regimes of continental climate.

All data sets contain measurements of global and diffuse solar irradiance on a horizontal surface, temperature and relative humidity. Measurements of surface albedo and atmospheric pressure at ground level are also available at the SURFRAD stations. Kipp and Zonen pyranometers (model CM-11) were employed to measure the global solar irradiance at the Almería and Granada stations, whereas Eppley ventilated pyranometers model PSP were employed for both down- and upwelling global and diffuse irradiance at the SURFRAD stations. At Almería's and Granada's stations, diffuse irradiance was measured by a Kipp and Zonen pyranometer (model CM-11) equipped with an Eppley shadow band model SBS. Because the shadow band screens the sensor from a portion of the incident diffuse radiation coming in from the sky, a correction was made to the measurements following Batlles et al. (1995). The SURFRAD stations used Eppley pyranometers mounted on Eppley automatic solar trackers model SMT-3 equipped with shade disks model SDK. Measurements of temperature, relative humidity and surface pressure were also made.

Data were recorded and averaged over different sampling intervals $(1,3,5$ and $10 \mathrm{~min})$. Values of direct irradiance were obtained from a difference of measured global and diffuse irradiance. Next, hourly mean values were calculated for all variables. Due to cosine response problems of radiometric sensors, we have only used cases corresponding to solar elevations higher than $5^{\circ}$. Finally, data associated with cloudless sky conditions were selected. To identify cloudless conditions, we used the normalised clearness index $k_{t}^{\prime}$ proposed by Perez et al. (1990):

$k_{t}^{\prime}=\frac{k_{t}}{1.031 \exp \left(\frac{-1.4}{0.9+9.4 / m_{a}},\right)+0.1}$

where $k_{t}$ is the hourly clearness index (defined as the ratio between horizontal global irradiance and horizontal extraterrestrial irradiance) and $m_{a}$ is the relative air mass given by 
Table 1. Geographical locations of the radiometric stations, period of measurement and number of hours associated with cloudless sky conditions.

\begin{tabular}{|c|c|c|c|c|c|c|c|}
\hline Station & Abbrev. & Country & Latitude $\left({ }^{\circ} \mathrm{N}\right)$ & Longitude $\left({ }^{\circ} \mathrm{O}\right)$ & Altitude (a.m.s.l.) & Years & Hours \\
\hline Almería & ALM & Spain & 36.83 & 2.41 & 0 & 1990-1998 & $\begin{array}{c}12880 \\
2052 *\end{array}$ \\
\hline Bondville & $\mathrm{BON}$ & US (IL) & 40.06 & 88.37 & 213 & 1996-1999 & $611 * *$ \\
\hline Desert Rock & DRA & US (NV) & 36.63 & 116.02 & 1007 & 1998-1999 & 3440 \\
\hline Fort Peck & FPK & US (MT) & 48.31 & 105.10 & 634 & 1996-1999 & 2815 \\
\hline Goodwin Creek & GWN & US (MS) & 34.25 & 89.87 & 98 & 1995-1999 & 2885 \\
\hline Granada & GRA & Spain & 37.18 & 3.58 & 660 & 1994-1995 & 3730 \\
\hline Penn State & PSU & US (PA) & 40.72 & 77.93 & 376 & 1998-1999 & 1190 \\
\hline Table Mountain & TBL & $\mathrm{US}(\mathrm{CO})$ & 40.13 & 105.24 & 1689 & 1995-1999 & 5878 \\
\hline
\end{tabular}

* - Broad-band solar irradiance data

** - AOT data

Kasten (1966) and corrected for local atmospheric pressure (Iqbal, 1983). A cloudless sky is then defined as $k_{t}^{\prime}>0.7$ (Molineaux et al., 1995). Obviously, some data may be erroneously included as a totally cloud-free atmosphere using this simple radiometric criterion. It is thus expected that this method does not detect, for instance, thin cloud covers as those due to cirrus clouds, which would have little effect on the measured global irradiance. Under these conditions, unrealistic higher turbidity levels would be observed.

\subsection{Spectral aerosol optical thickness data}

A second data set including aerosol optical thickness (AOT) at $0.440,0.500,0.640$ and $0.870 \mu \mathrm{m}$ were extracted from the automated Cimel CE-318 belonging to the AERONET and located at the Bondville radiometric station. The recording period was selected to match the SURFRAD broad-band radiation measurements from August 1996 through August 1999. The selected data corresponds to the quality assured level (Level 2.0) provided by the AERONET. Since several measurements per hour are available, hourly averaged values were obtained. Next, Bondville's AERONET and SURFRAD data sets were combined in such a way that their hourly values matched each other. A first filter was applied using Eq. (2) to select cloudless conditions, obtaining a data set with $1278 \mathrm{~h}$. To assure a totally cloud-free data set, from these days we performed a visual inspection on the daily evolution of the broad-band direct, diffuse and global irradiances recorded every $3 \mathrm{~min}$, screening out those suspected hours. After applying this second visual filter, a quality-controlled data set with 611 hourly averaged records was obtained.

Assuming $\alpha$ is constant throughout a given wavelength range, values of $\alpha$ and $\beta$ were derived by linear fit from the four AOT values taking in Eq. (1) natural logarithm:

$\ln \tau(\lambda)=\ln \beta-\alpha \ln \lambda$.
Values of $\alpha$ and $\beta$ calculated from AOTs data and using Eq. (3) will be referred to as $\alpha_{\text {sunphot }}$ and $\beta_{\text {sunphot }}$, respectively.

\section{Description of the algorithms to calculate coefficient $\beta$}

All three models considered herein (Dogniaux, 1974; Louche et al., 1987; Gueymard and Vignola, 1998) are well established. They have been adequately described in sufficient detail in the previously cited references. For the sake of clarity these models are described briefly in the following segment. Hereafter, we refer to each model by the name of the first author.

\subsection{Dogniaux's algorithm}

Dogniaux (1974) derived the following empirical relation for estimating Linke's turbidity factor using inputs of solar elevation $h$ (in degrees), precipitable water content $w$ (in $\mathrm{cm}$ ), and Ångström's turbidity coefficient $\beta$ :

$T_{L}=\left(\frac{85+h}{39.5 e^{-w}+47.4}+0.1\right)+(16+0.22 w) \beta$.

The Linke turbidity factor is defined as the number of Rayleigh atmospheres (an atmosphere clear of aerosols and without water vapor) required to produce a determined attenuation of direct radiation. This turbidity factor is related to measures of direct irradiance $I_{n}$ by means of the following equation:

$T_{L}=\frac{1}{\delta_{R} m_{a}} \ln \left(\frac{I_{0}}{I_{n}}\right)$,

where $I_{0}$ is the extraterrestrial normal irradiance and $\delta_{R}$ is the Rayleigh optical thickness. By using Eqs. (4) and (5), Ångström's turbidity coefficient $\beta$ may be obtained from values of direct irradiance and precipitable water content. It is interesting to note that the Rayleigh optical thickness $\delta_{R}$ 


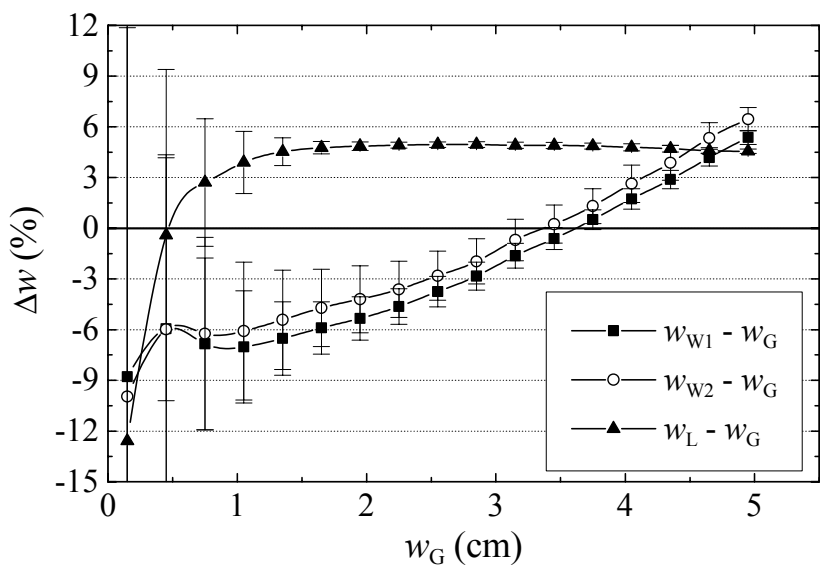

Fig. 1. Average relative differences of precipitable water estimated by Wright's (using two different algorithms to calculate $\mathrm{T}_{d}, w_{\mathrm{W} 1}$ and $\left.w_{\mathrm{W} 2}\right)$, Leckner's $\left(w_{\mathrm{L}}\right)$ and Gueymard's $\left(w_{\mathrm{G}}\right)$ methods against precipitable water estimated by Gueymard's method.

was calculated using the formula proposed by Kasten (1980). Previous analyses have shown that the use of the new equation given by Louche et al. (1986) and corrected by Kasten (1996) seems to be unsuitable to estimate $\beta$ from Eqs. (4) and (5). We refer to coefficient $\beta$ calculated by means of this method as $\beta_{\mathrm{D}}$.

\subsection{Louche's algorithm}

The method proposed by Louche et al. (1987) was derived from the model C by Iqbal (1983), but using the expression by Mächler (1983) for the transmittance due to aerosol attenuation. The Ångström turbidity coefficient obtained by Louche et al. (1987), $\beta_{\mathrm{L}}$, is expressed as:

$\beta_{L}=\frac{1}{m_{a} D} \ln \left(\frac{C}{A-B}\right)$,

where

$$
A=\frac{I_{n}}{0.9751 I_{0} T_{r} T_{o} T_{g} T_{w}},
$$

$B=0.12445 \alpha-0.0162$

$C=1.003-0.125 \alpha$,

$D=1.089 \alpha+0.5123$.

The transmittances by Rayleigh scattering $\left(T_{r}\right)$, ozone $\left(T_{o}\right)$, uniformly mixed gases $\left(T_{g}\right)$ and water vapor $\left(T_{w}\right)$ are given by the parametric model $C$ by Iqbal (1983). The transmittances $T_{r}$ and $T_{g}$ depend on air mass only; the transmittance $T_{o}$ needs information on ozone content, which may be calculated from location and time (Van Heuklon, 1979); the transmittance by water vapor $T_{w}$ uses air mass and precipitable water content as inputs. A value of $\alpha$ equal to 1.3 is assumed.

\subsection{Gueymard's algorithm}

From the spectral code SMARTS2 (Gueymard, 1995), Gueymard and Vignola (1998) proposed a method for estimating coefficient $\beta$ using measurements of global (or diffuse) and direct irradiance. The equation obtained is as follows:

$\beta_{G}=\frac{\sqrt{a_{1}^{2}-4\left(a_{2}-a_{3} K_{d b}\right)\left(a_{0}-K_{d b}\right)}}{2\left(a_{2}-a_{3} K_{d b}\right)}$,

where the coefficients $a_{i}$ depend on air mass and precipitable water. $K_{d b}$ is the standardised value (to zero altitude and total column ozone equal to $0.3434 \mathrm{~atm}-\mathrm{cm}$ ) of the ratio between diffuse and direct irradiance. Equation (11) is valid for values $\beta_{G} \leq 0.4$ and for a surface albedo equal to 0.15 . A correction is necessary if surface albedo is different (Gueymard and Vignola, 1998). The main novel feature of this method is an almost null dependence on precipitable water content. On the other hand, it is interesting to note that this parameterisation of $\beta$ is based on a fixed value of $\alpha$ equal to 1.3. Thus, this algorithm would at first be useful only for those locations with those aerosol characteristics. This limitation will be analysed in Sect. 5.2.

\section{Influence of differences in calculating precipitable water on turbidity estimates}

Total precipitable water $w$ is defined as the vertically integrated water vapor in a column extending from the surface to the top of the atmosphere. In order to estimate the turbidity coefficient $\beta$ from broad-band solar radiation measurements, knowledge of total precipitable water in the atmosphere is needed. In the absence of an atmospheric sounding or solar spectral measurements, the linear relationship between the logarithm of $w$ and dew point temperature $T_{d}$, has been often used to calculate precipitable water (Iqbal, 1983):

$\ln w=a+b T_{d}$.

Parameters $a$ and $b$ are not universal and thus they should be calculated for every place and for a specific sampling time. Nevertheless, several authors (Molineaux et al., 1995; Mottus et al., 2001; Marion and George, 2001; Lopez et al., 2001) have employed Eq. (12) using those values of the parameters obtained for Albany NY by Wright et al. (1989), $a=-0.0756$ and $b=0.0693$, and which were suitable for estimating instantaneous precipitable water under cloudless skies. In addition to the errors of estimate associated with local parameters $a$ and $b$, a second source of error is due to the method of calculating dew point temperature. In general terms, $T_{d}$ is related to temperature $T$ and relative humidity $\Phi$ by means of saturation pressure of water vapor $p_{s}$ :

$p_{s}\left(T_{d}\right)=p_{v}(T)=\Phi p_{s}(T)$,

where $p_{v}$ is the partial pressure of water vapor. If measurements of $T_{d}$ are not available, Eq. (13) can be used to calculate it. Values of $p_{s}$ may be obtained from tables (ASHRAE, 
1989) or calculated from some formulas proposed in the literature. This second option is more suitable for computing calculations. Gueymard (1993) analysed a wide variety of such algorithms. Among those, the Magnus type and Leckner equations are common expressions used for calculating $p_{s}$. They read, respectively, as:

$p_{s}^{\text {(Magnus) }}=6.107 \exp \left(\frac{17.38 T}{239+T}\right){ }^{1}$,

$p_{s}^{\text {(Leckner) }}=0.01 \exp \left(26.23-\frac{5416}{273.15+T}\right)$,

where $p_{s}$ is expressed in mbar and $T$ in degrees Celsius. Using $p_{s}^{\text {(Magnus) }}$ or $p_{s}^{\text {(Leckner) }}$ in Eq. (13), different relations between dew point temperature and surface temperature and relative humidity are thus obtained:

$$
\begin{aligned}
& T_{d}^{(\text {Magnus })}=\frac{239 f(T, \Phi)}{17.38-f(T, \Phi)} \\
& , \quad f(T, \Phi)=\ln \Phi+\frac{17.38 T}{239+T} \\
& T_{d}^{(\text {Leckner })}=\frac{5416}{5416 /(T+273.15)-\ln (\Phi)}-273.15,
\end{aligned}
$$

where relative humidity is in fractions of one. Precipitable water calculated by using Wright's formula and dew point temperature estimated by Magnus' or Leckner's equation is referred to as $w_{\mathrm{W} 1}$ and $w_{\mathrm{W} 2}$, respectively.

Another alternative method often used to calculate the amount of precipitable water is given by Leckner (1978). Leckner's correlation expresses the precipitable water in terms of relative humidity:

$w_{L}=49.3 \frac{\Phi p_{s}^{(\text {Leckner })}}{T}$,

where $T$ is in Kelvin. More recently, Gueymard (1994) introduced a new relationship between $w$ and the surface temperature and relative humidity given by:

$w_{G}=21.67 H_{v} \frac{\Phi p_{s}^{(\text {Gueymard })}}{T}$,

where $p_{s}^{\text {(Gueymard) } 2}$ and $H_{v}$ are, respectively, given by the following formulas:

$\ln p_{s}^{(\text {Gueymard })}=22.33-49.14 \frac{1}{T_{0}}-10.922 \frac{1}{T_{0}^{2}}-0.3902 T_{0}$

$H_{v}=0.4976+1.5265 \theta+\exp \left(13.6897 \theta-14.9188 \theta^{3}\right)(21)$

\footnotetext{
${ }^{1}$ The new constants are given by Gueymard (1993).

${ }^{2}$ The coefficients of $\ln p_{s}^{\text {(Gueymard) }}$ have been rounded off from their original values in order to simplify this expression. Relative errors of this modified $p_{S}$ with regard to the original $p_{s}$ values by Gueymard (1994) are lower than $0.035 \%$ for temperature values ranging from -40 to $60^{\circ} \mathrm{C}$.
}
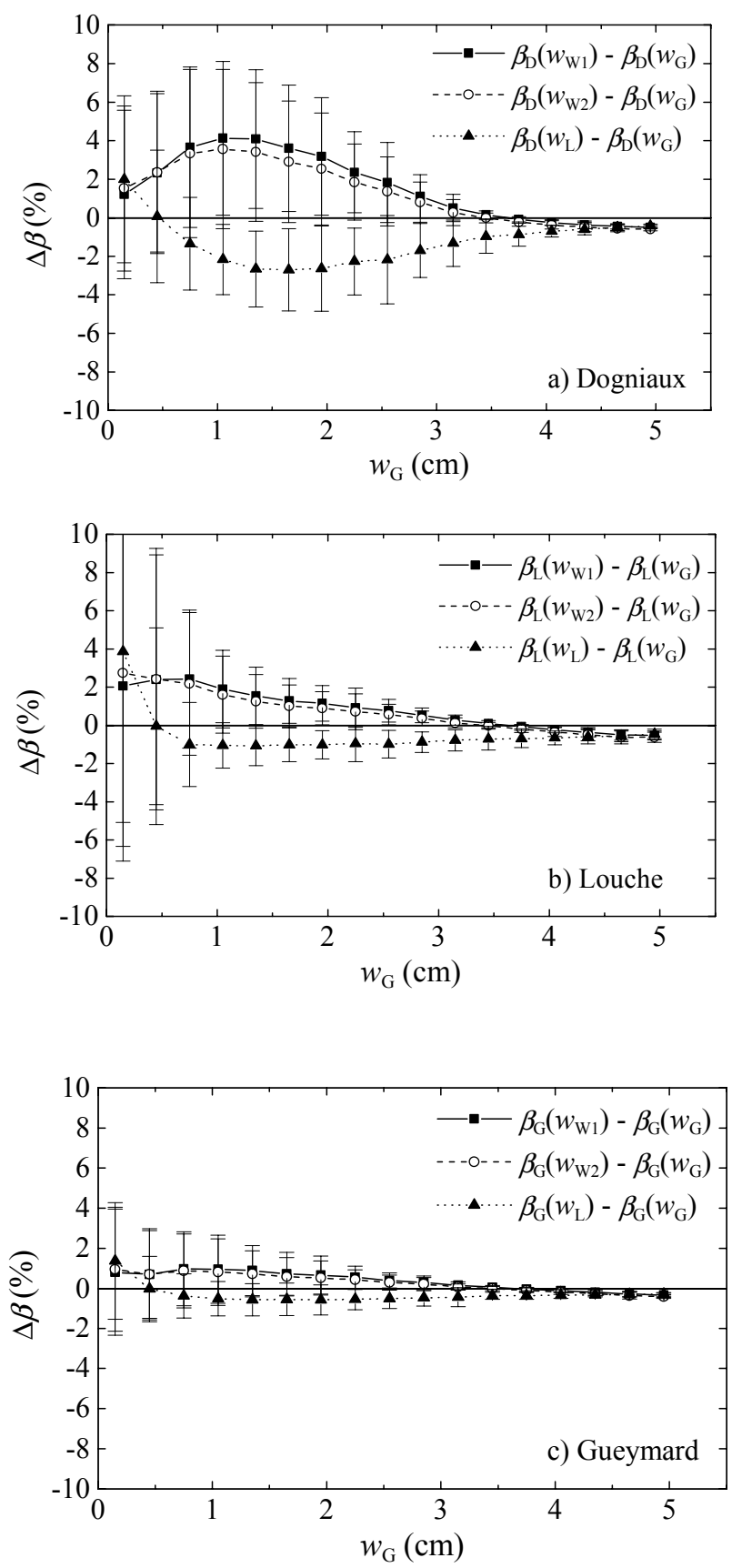

Fig. 2. Average relative differences (as legends inside of the figures refer to) against precipitable water calculated by Gueymard's method for each turbidity algorithm.

where $T_{0}=T / 100, \theta=T / 273.15$ and $T$ is expressed in Kelvin.

In order to analyse the differences in calculating precipitable water by using each method described above, Fig. 1 shows the average relative differences $w_{\mathrm{W} 1}-w_{\mathrm{G}}, w_{\mathrm{W} 2}-w_{\mathrm{G}}$, $w_{\mathrm{L}}-w_{\mathrm{G}}$ (expressed as a percentage of $w_{\mathrm{G}}$ ) against precipitable water calculated by Gueymard's method, $w_{\mathrm{G}}$, using the whole database. Standard deviations of the mean are also included. It is noted that the use of both Magnus' or 
Leckner's equation for calculating dew point temperature implies differences lower than $1.5 \%$ on the values of precipitable water estimated by means of Wright's correlation. In fact, average deviations between $T_{d}^{\text {(Magnus) }}$ and $T_{d}^{\text {(Leckner) }}$ are less than $0.2^{\circ} \mathrm{C}$. Since deviations on precipitable water calculated by means of Wright's correlation is given by $\Delta w_{\mathrm{W}}=0.0693 w \Delta T_{d}$, average differences around $0.2^{\circ} \mathrm{C}$ on $T_{d}$ leads to relative errors lower than $1.5 \%$. For $w_{\mathrm{G}}>1 \mathrm{~cm}$, relative differences between Wright's correlation and Gueymard's method present a linear trend ranging from $-6 \%$ to $6 \%$. The use of $T_{d}^{\text {(Leckner) }}$ in Wright's correlation provides estimates slightly closer to those from Leckner's and Gueymard's approaches than those corresponding to the use of $T_{d}^{\text {(Magnus) }}$. On the other hand, relative differences between Leckner's approach and Gueymard's method present an almost constant value around $4-5 \%$ for this region of precipitable water. Since the spectral absorption bands of water vapor rapidly saturate as the amount of water vapor increases, these differences are expected to be of minor relevance in estimating $\beta$. For $0.5<w_{\mathrm{G}}<1 \mathrm{~cm}$, Leckner's approach provides average values closer to those by Gueymard's method with respect to Wright's correlation. However, both Leckner's and Wright's approach exhibit large standard deviations, which may lead to an inverse situation under several local atmospheric conditions. For $w_{\mathrm{G}}<0.5 \mathrm{~cm}$, Wright's and Leckner's algorithms present average relative differences around $-9 \%$ and $-13 \%$, respectively, and higher standard deviations with respect to Gueymard's method. Differences between Leckner's and Gueymard's methods to calculate precipitable water agree with those reported by Gueymard and Garrison (1998) for Montreal.

In order to analyse the influence of precipitable water differences on turbidity estimates by using Dogniaux's, Louche's and Gueymard's approaches independently, the following relative differences between turbidity estimates $\Delta \beta_{i}$ for every one of these approaches ( $\mathrm{i}=\mathrm{D}, \mathrm{L}$ or $\mathrm{G}$ ) and employing, respectively each of the above precipitable water methods were obtained: ${ }^{3}$.

$\Delta \beta_{i}=\frac{\beta_{i}\left(w_{j}\right)-\beta_{i}\left(w_{G}\right)}{\beta_{i}\left(w_{G}\right)}$,

where $\mathbf{j}\left(=w_{\mathrm{W} 1}, w_{\mathrm{W} 2}\right.$ or $\left.w_{\mathrm{L}}\right)$ refers to the precipitable water method used.

Figure 2 shows the average relative differences (expressed as percentage) against $w_{\mathrm{G}}$ for each turbidity approach. Standard deviations of the mean are also included. It is noted that the three turbidity methods present a negligible dependence on precipitable water differences for higher precipitable water values, as was expected. As $w_{\mathrm{G}}$ decreases, Gueymard's turbidity method provides the lowest values of the average turbidity relative differences and standard deviations with a slight increase in standard deviation. Average turbidity relative differences and standard deviations from Louche's algorithm present a trend similar to those from Gueymard's

\footnotetext{
${ }^{3}$ Relative differences corresponding to $\beta\left(w_{\mathrm{G}}\right)<0.002$ were removed to avoid large values of $\Delta \beta_{i}$.
}

method but standard deviations are dramatically increased as $w_{\mathrm{G}}$ decreases below $0.7 \mathrm{~cm}$. On the other hand, Dogniaux's method presents the higher increase in average turbidity relative differences and standard deviations as $w_{\mathrm{G}}$ ranges from $2.5 \mathrm{~cm}$ to $0.7 \mathrm{~cm}$; as $w_{\mathrm{G}}$ decreases below $0.7 \mathrm{~cm}$, these values are not strongly affected for the large increase in precipitable water relative differences and standard deviations. Therefore, these results point to Gueymard's turbidity method to be the less dependent on precipitable water differences, whereas Dogniaux's and Louche's methods appear to be more sensitive to the precipitable water method selected for $0.7<w_{\mathrm{G}}<2.5 \mathrm{~cm}$ and $w_{\mathrm{G}}<0.7 \mathrm{~cm}$, respectively.

\section{Comparison of the turbidity algorithm performances}

\subsection{Comparison procedure 1}

The comparison of the performance of the turbidity algorithms was initially undertaken by analysing the corresponding turbidity estimates between each other. For that and hereafter, all three methods used precipitable water estimates by Gueymard's approach. Figure 3 shows turbidity values calculated, respectively, by Dogniaux's and Gueymard's algorithms against those estimated by Louche's algorithm using the whole database. For a better comparison, the coefficient of determination $r^{2}$, the root mean square error RMSE and the mean bias error MBE between $\mathrm{y}$ - and $\mathrm{x}$-values are also included. These statistical tests were computed as an average of each $r^{2}$, RMSE and MBE value calculated separately at each location. In addition, the standard deviation of each statistical test is added as well. Standard deviation provides information about how tightly all the independent values are clustered around the mean and thus how representative the statistical tests are for every location.

From Fig 3a, it may be seen that the simple Dogniaux's correlation provides hourly turbidity estimates quite similar to those calculated by Louche's algorithm, with a higher coefficient of determination $r^{2}=0.973 \pm 0.006$. The low standard deviation means this result is highly representative and thus, a good match between both turbidity estimates is expected for every location. The mean value of the MBE equal to $0.003 \pm 0.007$ denotes turbidity values by Dogniaux's correlation overestimate slightly those obtained using Louche's algorithm at most locations. However, the higher standard deviation with respect to the mean value points out the opposite tendency was found at some locations.

A more detailed analysis of the differences $\beta_{\mathrm{D}}-\beta_{\mathrm{L}}$ has shown that these differences exhibit a similar dependence on precipitable water at each locations, such as it is derived from Fig. 4. After removing this dependence, it could be expected that turbidity estimates by Dogniaux's correlation and those by Louche's algorithm present closer hourly values to each other. For that, the following quadratic-fitted curve was obtained using all average differences from each location other than Table Mountain

$$
\Delta \beta_{D-L}=\beta_{D}-\beta_{L}=0.028-0.022 w_{G}+0.003 w_{G}^{2} .
$$



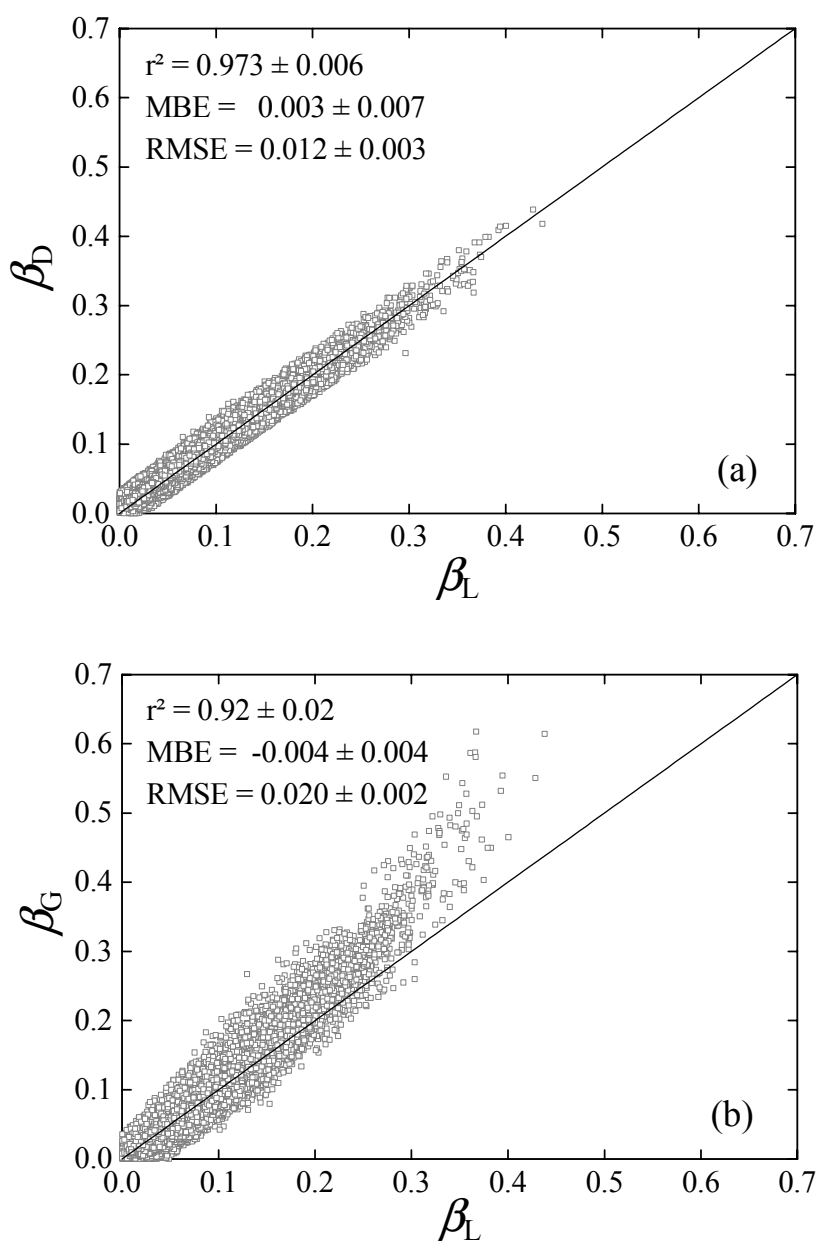

Fig. 3. Comparison between hourly turbidity estimates by using Dogniaux's, Louche's and Gueymard's algorithms.

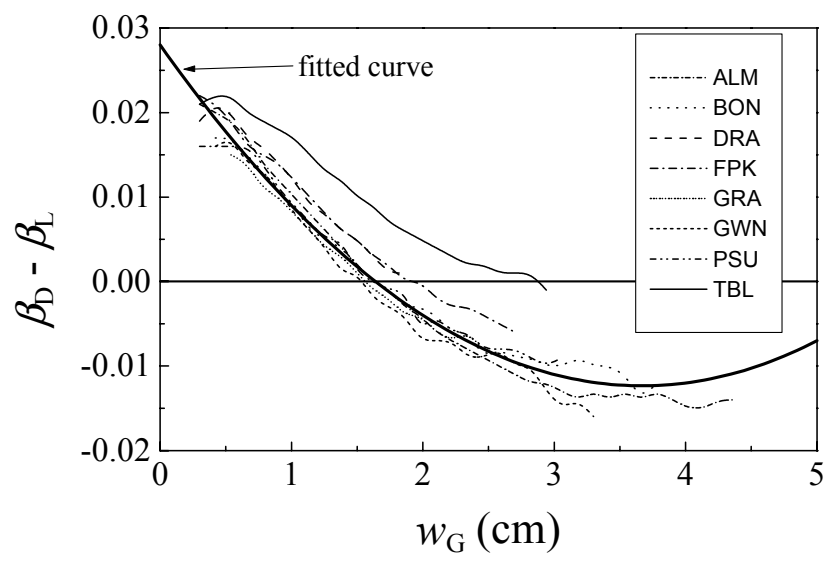

Fig. 4. Average differences between turbidity estimates by Dogniuax's correlation and Louche's algorithm versus precipitable water by Gueymard's approach for each location.

Figure 5 shows $\beta_{\mathrm{D}}^{\prime}=\beta_{\mathrm{D}}-\Delta \beta_{\mathrm{D}-\mathrm{L}}$ versus $\beta_{\mathrm{L}}$. Statistical tests in the above sense are also included. It may be seen that the spread of the data points is reduced. Indeed, the new co-

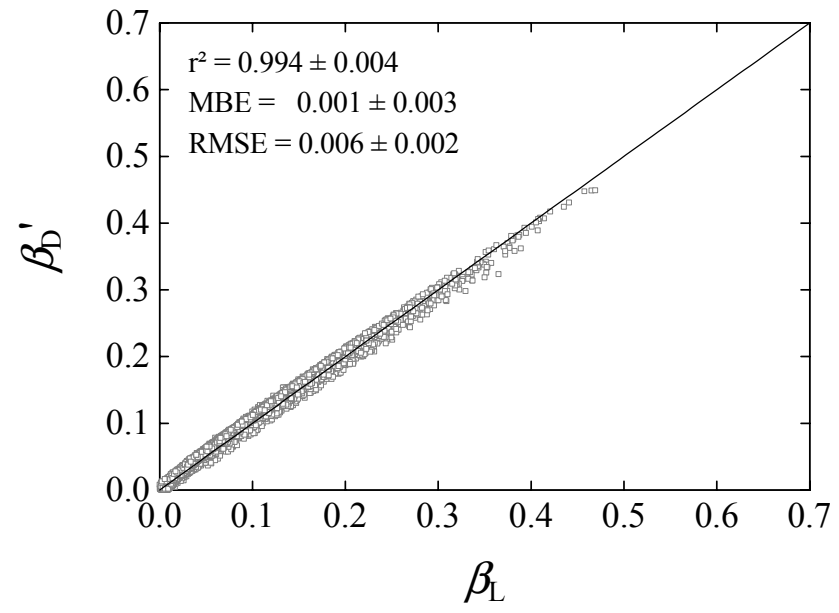

Fig. 5. Comparison between hourly turbidity estimates by using Dogniaux's correlation modified by Eq. (22) and Louche's algorithm.

efficient of determination is increased from 0.973 to 0.994 , and the corresponding standard deviation is slightly diminished. The MBE and RMSE (along with the corresponding standard deviations) are also reduced with values equal to $0.001 \pm 0.003$ and $0.006 \pm 0.002$.

On the other hand, Louche's and Gueymard's algorithms present higher differences to each other as it is derived from Fig. $3 \mathrm{~b}$ and the values of the statistical test. The relationship between both turbidity estimates presents a higher spread of the data points such as the lower coefficient of determination $\left(\mathrm{r}^{2}=0.92 \pm 0.02\right)$ and the higher RMSE $(0.020 \pm 0.002)$ prove. In addition to the different formulation of both algorithms, a second source leading to this spread is associated with cloud interference affecting in a different way the estimates of $\beta$, which is not present between Dogniaux's and Louche's methods. This assumption will be analysed in the next section. A mean value of the MBE equal to $-0.004 \pm 0.004$ denotes Gueymard's approach underestimates $\beta$ values with respect to Louche's algorithm for almost every locations. It is interesting, however, to note that Gueymard's approach tends to overestimate the turbidity values calculated by Louche's algorithm in the region of higher turbidity levels at each location. This result would be again associated with cloud interference. In this sense and such as it was noted earlier, the use of hourly global irradiance data alone to identify cloudless skies is not sufficient to provide a totally cloud free atmosphere which is needed for an accurate performance of Gueymard's algorithm.

We have also analysed the influence of random experimental errors in pyranometer measurements on turbidity estimates. To simulate experimental errors, we have added a Gaussian noise to both global and diffuse irradiance measurements, in such a way that both of them present a maximum deviation of about $\pm 5 \%$ with regard to the original data. Figure 6a shows the frequency distribution of the errors in the estimated direct irradiance and expressed as a percentage of 

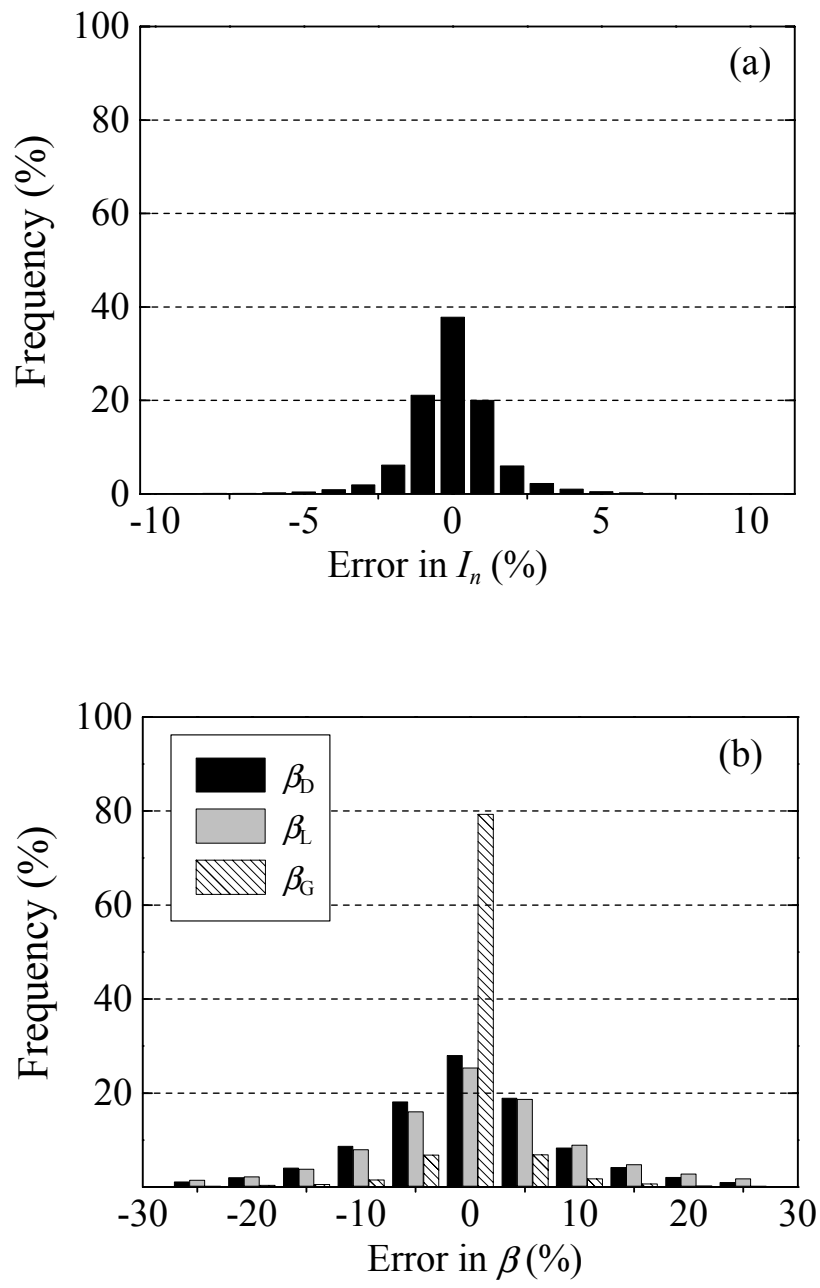

Fig. 6. Percentage frequency distribution of errors in: (a) hourly direct irradiance; (b) turbidity coefficient estimated by each algorithm, as pyranometer measurements are affected by a Gaussian random signal.

the original values. These errors exhibit a frequency distribution similar to those shown by global and diffuse irradiances. Figure $6 \mathrm{~b}$ shows the frequency distribution of the propagated errors in the values of the turbidity coefficient estimated by each algorithm. It may be seen that uncertainties in irradiance measurements has a minimal effect on Gueymard's algorithm, with almost $80 \%$ of the data associated with relative variations of $\pm 2.5 \%$. Dogniaux's and Louche's algorithms appear to be more sensitive to those uncertainties, displaying errors of $\pm 10 \%$ for the $80 \%$ of the data.

\subsection{Comparison procedure 2}

Using SURFRAD and AERONET data from the Bondville station, a comparison between estimated hourly values of $\beta$ by using each broad-band turbidity algorithm and values of $\beta$ derived from AOT records, $\beta_{\text {sunphot }}$, was undertaken in terms of the statistical tests employed in the previous section. The results are shown in Fig. 7. RMSE and MBE have also been
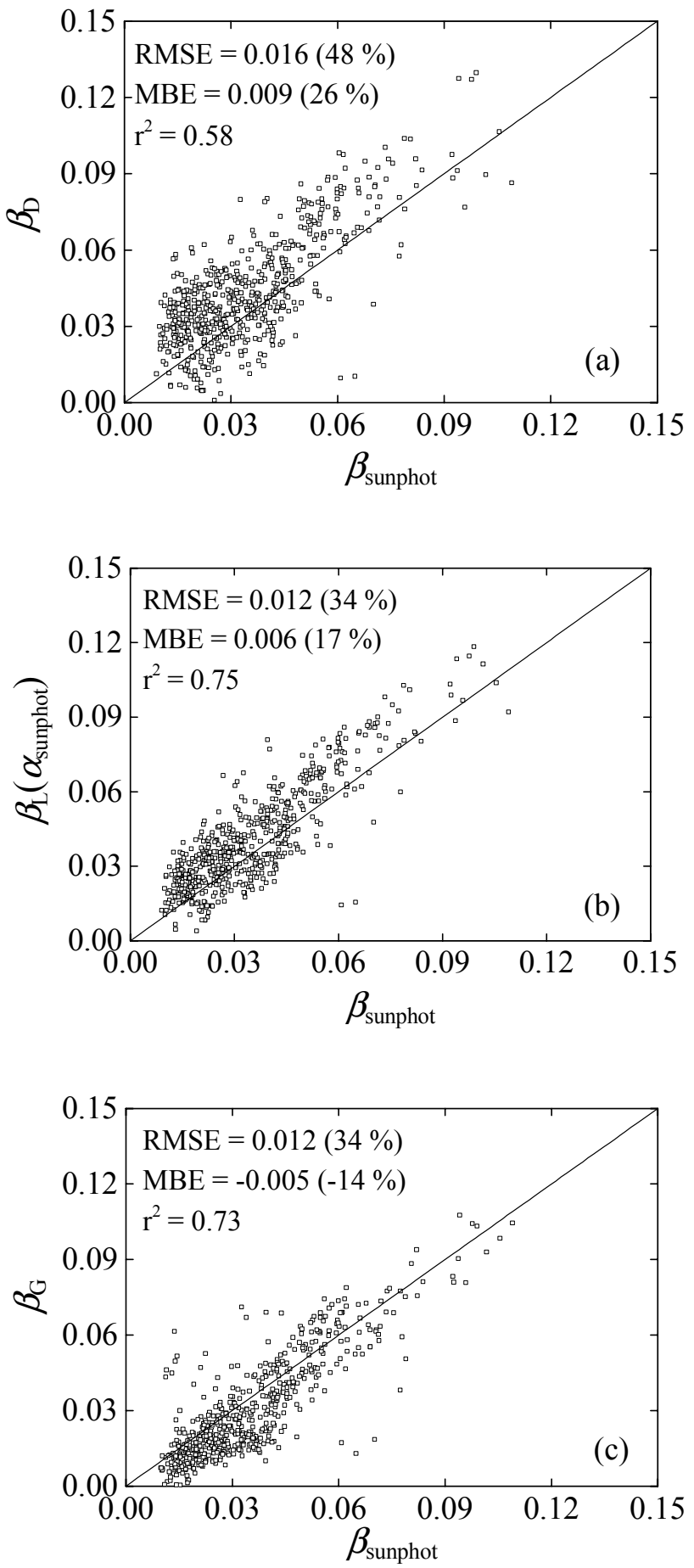

Fig. 7. Hourly turbidity estimates by using Dogniaux's (a), Louche's (b) and Gueymard's (c) algorithms versus turbidity values derived from sunphotometric measurements at Bondville $\left(\beta_{L}\right.$ was calculated employing values of $\alpha$ obtained from sunphotometric measurements).

expressed as a percentage of the mean value of $\beta_{\text {sunphot }}$. Dogniaux's algorithm presents the higher spread and deviation regard to $\beta_{\text {sunphot }}$ as the RMSE and MBE values prove. Both Louche's and Gueymard's models improve the estimates, 


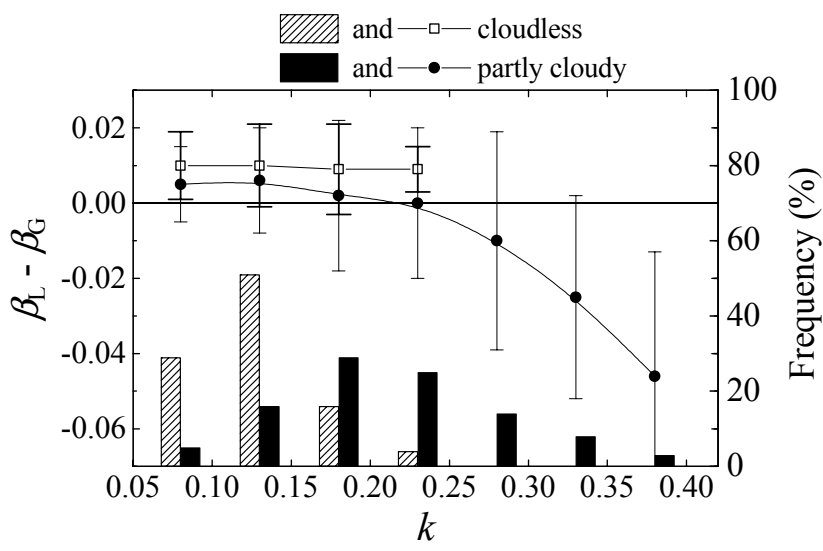

Fig. 8. Average differences $\beta_{\mathrm{L}}\left(\alpha_{\text {sunphot }}\right)-\beta_{G}$ versus the hourly diffuse fraction $k$ for both totally cloud-free and partly cloudy sky conditions. Percentage frequency distribution of the diffuse fraction for the two types of sky conditions is also included.

reducing the RMSE around 14\% and increasing the coefficient of determination around $17 \%$. Moreover, these latter models provide a lower deviation. In this regard, Gueymard's algorithm underestimates values of $\beta_{\text {sunphot }}$ around $-14 \%$, whereas Louche's algorithm exhibits the opposite tendency with an overestimation of about $17 \%$.

It is important to note that values of $\beta_{\mathrm{L}}$ used in this section were calculated using hourly records of $\alpha$ from AERONET measurements, instead of a mean value equal to 1.3. This is the reason for the improvement in Louche's algorithm performance with respect to Dogniaux's one. If $\alpha$ is set to 1.3, the RMSE and MBE values corresponding to Louche's algorithm are $44 \%$ and $26 \%$, respectively, whereas if $\alpha=1.7$ (the more frequent value of $\alpha_{\text {sunphot }}$ at Bondville for the selected period), then $\mathrm{RMSE}=32 \%$ and $\mathrm{MBE}=11 \%$, being $\mathrm{r}^{2}=0.73$ in both cases. The wavelength exponent plays thus an important role in the performance of Louche's algorithm, leading to an improvement in the estimates against those by Gueymard's algorithm by using a proper value of $\alpha$. Moreover, since the statistical results for the performance of the Gueymard's algorithm are similar to those for the performance of the Louche's algorithm using sunphotometric values of the wavelength exponent, it is derived that Gueymard's algorithm is less sensitive to variations in the wavelength exponent, even being based on a fixed value of 1.3. Nevertheless, this result should be studied using data from other sites and with different climatic conditions.

On the other hand, cloud interference has a different influence on Louche's and Gueymard's algorithms, as it was noted in the previous section. To analyse this influence, we used two hourly data sets: one corresponding to a totally cloud-free sky (the data set filtered by visual inspection $611 \mathrm{~h}-$ ), and the other one associated with only partly cloudy conditions. This latter data set was obtained by removing the above totally cloudless data from the data filtered by the radiometric criterion given by Eq. (2). Figure 8 shows the average differences $\beta_{\mathrm{L}}\left(\alpha_{\text {sunphot }}\right)-\beta_{\mathrm{G}}$ against the hourly diffuse fraction $k$ (defined as the ratio between diffuse and global solar irradiances on a horizontal surface) for both sky conditions. In addition, we have included the percentage frequency distribution of the diffuse fraction for the two data sets for a better comparison. The diffuse fraction is used as a parameter sensitive to the amount of clouds. Because of the dependency of the hourly diffuse fraction on solar elevation, we used only cases with solar elevation angles above $20^{\circ}$. It is observed that under totally cloudless conditions, differences are constants for every value of $k$. As cloud interferences exist, values of both turbidity and diffuse fraction tend to increase. Under these conditions, Louche's algorithm appears to be less sensitive such as it is derived from the reduction in the differences for $k<0.15$ with regard to the above constant trend and the notable increasing deviation in the differences as the diffuse fraction is increased.

\subsection{Comparison of monthly mean values}

As a final step in our comparative study, we have taken into account that many climatical works deal with long-term variations in atmospheric turbidity (Fox, 1994; Jacovides and Karalis, 1996; Persson, 1999; Devara et al., 2002). In this sense, to examine the long-term differences between each turbidity algorithm, we compared the annual evolution of monthly mean values of $\beta$ at each location, respectively (Fig. 9). It may be seen that all three algorithms provide trends similar to each other but with small differences. At Almería, Goodwin Creek, Granada, Penn State and Table Mountain, turbidity presents a seasonal variation with a minimum for the winter months and a maximum during the summer due mainly to the increase in water vapor content associated with the higher temperatures. This variation is more accentuated at Goodwin Creek. On the other hand, Desert Rock exhibits the lowest turbidity levels along with an almost constant trend during the entire year. Bondville and Fort Peck seem to present any annual cycle (at least for the selected months), showing relative maximum and minimum turbidity levels in both summer and winter. It is interesting to note the higher turbidity at Almería during 1992. This turbidity increase is associated with the eruption of Mount Pinatubo in June 1991, which injected into the stratosphere a large amount of volcanic aerosols (Olmo and Alados-Arboledas, 1995).

\section{Conclusions}

Atmospheric turbidity is often expressed in terms of the Ångström turbidity coefficient $\beta$. To calculate coefficient $\beta$ in the absence of measurements of spectral solar radiation, different algorithms based on data of broad-band solar radiation and meteorological parameters can be used. The aim of this article has focused on the comparison and evaluation of three of these turbidity algorithms.

First, we contrast three approaches for computing precipitable water content. Results show that Wright's correlation 

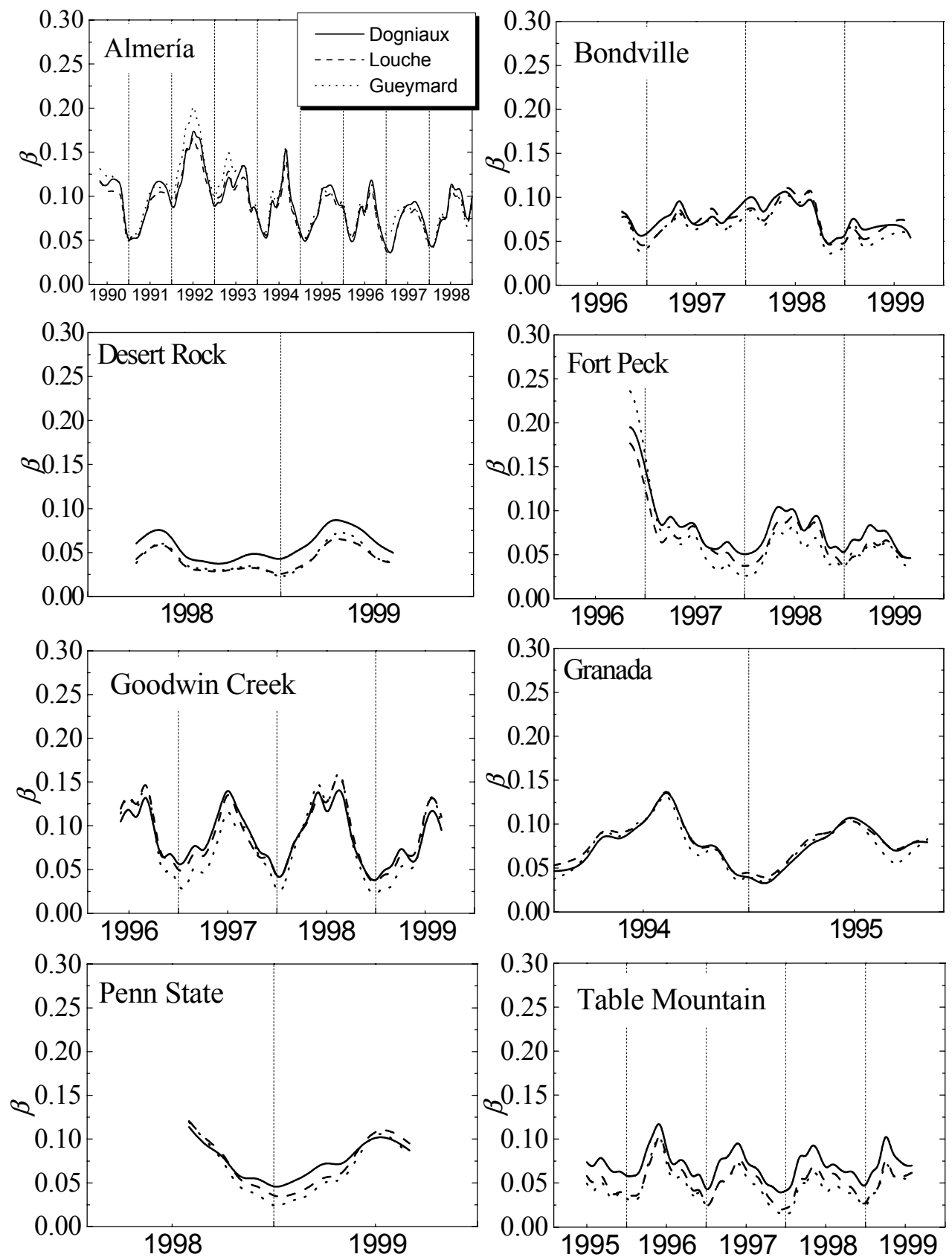

Fig. 9. Annual evolution of monthly mean values of turbidity coefficient $\beta$ calculated by each turbidity algorithm at each location.

provides hourly values of precipitable water slightly closer to those computed by Leckner's and Gueymard's approaches, if dew point temperature is estimated by Leckner's formula instead of by Magnus' equation. The three approaches show greater relative differences between each other for low precipitable water, and smaller relative differences between each other for high precipitable water.

Gueymard's algorithm proved to be the less dependent on precipitable water differences. The pattern of turbidity differences against precipitable water from Louche's algorithm was also similar to that by Gueymard's method, although for precipitable water values less than about $0.5 \mathrm{~cm}$, a large uncertainty in turbidity estimates was founded. In contrast, Dogniaux's formula appeared to be the most affected by precipitable water differences for precipitable water values between about $1 \mathrm{~cm}$ and $2 \mathrm{~cm}$. Nevertheless, all three turbidity algorithms have shown to be independent on precipitable water differences for higher values of precipitable water, as a consequence of the saturation effect shown by the spectral absorption bands of water vapor. Therefore, in humid climates, the use of any of these methods for calculating precipitable water would lead to negligible differences in turbidity estimates by any of the analysed turbidity algorithms. 
On the other hand, we have found that Dogniaux's and Louche's algorithms provide hourly turbidity estimates closer to each other than by using Gueymard's method. Moreover, differences on turbidity estimates by Dogniaux's and Louche's algorithms were notably reduced by introducing a correction term depending on precipitable water. Similarly, random errors in pyranometer measurements have a similar and significant effect on the performance of these latter models. In contrast, the influence of those random uncertainties on turbidity estimates by Gueymard's method has shown to be of minor importance.

Comparison of estimated turbidity values against turbidity values derived from aerosol optical thickness data has shown that the performance of the algorithm by Louche et al. (1987) is significantly improved by setting $\alpha$ to the more frequent hourly value obtained for the location. In such conditions, Louche's and Gueymard's methods present a similar RMSE of around $34 \%$. In addition, both algorithms exhibit similar absolute deviations with values of $17 \%$ and $-14 \%$ respectively. Setting $\alpha$ to 1.3 , the algorithm by Louche et al. (1987) performs similar to that by Dogniaux (1974) with RMSE and MBE values of $48 \%$ and $25 \%$. Thus, Gueymard's method is the more accurate and reliable, if information about the wavelength exponent is not available. On the other hand, turbidity algorithms by Dogniaux (1974) and Louche et al. (1987) have shown to be less sensitive to broadband solar radiation data affected by cloud interference than that by Gueymard and Vignola (1998). Nevertheless, if only a study of annual evolution of the turbidity based on monthly values is to be performed, we have found that all three algorithms are suitable for achieving this task.

Acknowledgements. The authors are grateful to SURFRAD's staff for providing the solar radiation database. The authors thank B. N. Holben for his effort in establishing and maintaining the AERONET site at Bondville. This work was accomplished thanks to the project (REN/2001)-3890-C02-01/CLI of the Ministerio de Ciencia y Tecnología of Spain. The authors thank the valuable suggestions by the anonymous referees.

Topical Editor O. Boucher thanks two referees for their help in evaluating this paper.

\section{References}

Ångström, A.: On the atmospheric transmission of sun radiation and in dust in the air, Geogr. Ann., 2, 156-166, 1929.

Augustine, J. A., DeLuisi, J. J., and Long, C. N.: SURFRAD A national surface radiation budget network for atmospheric research, The Bulletin of the American Meteorological Society, 81, 2341-2358, 2000.

ASHRAE: Psychometrics, Handbook of Fundamentals, Refrigerating and Air-Conditioning Engineers, American Society of Heating, 1989.

Batlles, F. J., Alados-Arboledas, L., and Olmo, F. J.: On shadowband correction methods for diffuse irradiance measurements, Solar Energy, 54, 105-114, 1995.

Batlles, F. J., Olmo, F. J., Tovar, J., and Alados-Arboledas, L.: Comparison of cloudless sky parameterisation of solar irradiance at various Spanish midlatitude Locations, Theor. Appl. Climatol., 66, 81-93, 2000.

Cachorro, V. E., de Frutos, A. M., and Casanova, J. L.: Determination of the Ångström turbidity parameters, Appl. Opt., 26, 30693076, 1987.

Devara, P. C. S., Maheskumar, R. S., Raj, P. E., Pandithurai, G., and Dani, K. K.: Recent trends in aerosol climatology and air pollution as inferred from multi-year lidar observations over a tropical urban station, Int. J. Climatol., 22, 435-449, 2002.

Dogniaux, R.: Representation analytique des composantes du rayonnement solaire. Institut Royal de Métèorologie de Belgique, Série A No. 83, 1974.

Fox, J. D.: Calculated Ångström turbidity coefficients for Fairbanks, Alaska, J. Climate, 7, 1506-1512, 1994.

Gueymard, C., Assessment of the accuracy and computing speed of simplified saturation vapor equations using a new reference dataset, J. Appl. Meteorol., 32, 1294-1300, 1993.

Gueymard, C.: Analysis of monthly atmospheric precipitable water and turbidity in Canada and northern United States. Solar Energy 53, 57-71, 1994.

Gueymard, C.: SMARTS2, A simple model of the atmospheric radiative transfer of sunshine: algorithms and performance assessment, Report FSEC-PF-270-95, Florida Solar Energy Center, Cocos, FL, 1995.

Gueymard, C. and Garrison, J. D.: Critical evaluation of precipitable water and atmospheric turbidity in Canada using measured hourly solar irradiance. Solar Energy 62, 291-307, 1998.

Gueymard, C. and Vignola, F.: Determination of atmospheric turbidity from the diffuse-beam broad-band irradiance ratio. Solar Energy 63, 135-146, 1998.

Holben B. N., Eck, T. F., Slutsker, I. Tanre, D., Buis, J. P., Setzer, A., Vermote, E., Reagan, J. A., Kaufman, Y., Nakajima, T., Lavenu, F., Jankowiak, I., and Smirnov, A.: AERONET - A federated instrument network and data archive for aerosol characterization, Rem. Sens. Environ., 66, 1-16, 1998.

Iqbal, M.: An introduction to solar radiation, Academic Press, Toronto, 1983.

Jacovides, C. P. and Karalis, J. D.: Broad-band turbidity parameters and spectral band resolution of solar radiation for the period 1954-1991, in Athens, Greece, Int. J. Climatol. 16, 229-242, 1996.

Janjai, S., Kumharm, W., and Laksanaboonsong, J.: Determination of Ångström's turbidity coefficient over Thailand, Renew. Energy, 28, 1685-1700, 2003.

Kasten, F.: A new table and approximate formula for relative optical air mass, Arch. Meteorol. Geophys. Bioklimatol., Ser. B, 14, 206-223, 1966.

Kasten, F.: A simple parameterization of the pyrheliometric formula for determining the Linke turbidty factor, Meteor. Rundschau. 33, 124-127, 1980.

Kasten, F.: The Linke turbidity factor based on improved values of the integral Rayleigh optical thickness, Solar Energy 56, 239244, 1996.

Leckner, B.: The spectral distribution of solar radiation at the earth's surface - elements of a model, Solar Energy 20, 143-150, 1978.

Li, D. H. W. and Lam, J. C.: A study of atmospheric turbidity for Hong Kong, Renew. Energy 25, 1-13, 2002.

Linke, F.: Transmission Koeffizient und Trübungsfaktor, Beitr. Phys. Atmos., 10, 91-103, 1922.

López, G., Rubio, M. A., Martínez, M. and Batlles, F. J.: Estimation of hourly global photosynthetically active radiation using ar- 
tificial neural network models, Agric. For. Met., 107, 279-291, 2001.

Louche, A., Peri, G. and Iqbal, M.: An analysis of the Linke turbidity factor, Solar Energy, 37, 393-396, 1986.

Louche, A., Maurel, M., Simonnot, G., Peri, G. and Iqbal, M.: Determination of Ångström turbidity coefficient from direct total solar irradiance measurements, Solar Energy, 38, 89-96, 1987.

Mächler, M. A.: Parameterization of solar radiation under clear skies, M. A. Sc. Thesis, University of British Columbia, Vancouver, Canada, 1983.

Marion, W. and George, R.: Calculation of solar radiation using a methodology with worldwide potential, Solar Energy, 71, 275283, 2001.

Molineaux, B., Ineichen, P., Delaunay, J. J.: Direct luminous efficacy and atmospheric turbidity - improving model performance, Solar Energy, 55, 125-137, 1995.

Mottus, M., Ross, J. and Sulev, M., Experimental studio of ratio of PAR to direct integral solar radiation under cloudless conditions, Agric. For. Met., 109, 161-170, 2001.

Olmo, F. J. and Alados-Arboledas, L.: Pinatubo eruption effects on solar radiation at Almería $\left(36.83^{\circ} \mathrm{N}, 2.41^{\circ} \mathrm{W}\right)$, Tellus B, 47 , 602-606, 1995.

Pedrós, R., Utrillas, M. P., Martínez-Lozano, J. A., and Tena, F.: Values of broad band turbidity coefficients in a Mediterranean coastal site, Solar Energy, 66, 11-20, 1999.
Perez, R., Ineichen, P., Seals, R. and Zelenka, A.: Making full use of the clearness index for parameterizing hourly insolation conditions, Solar Energy, 45, 111-114, 1990.

Persson, T.: Solar radiation climate in Sweden, Phys. Chem. Earth B. 24, 275-279, 1999.

Pinazo, J. M., Cañada, J., and Bosca, J. V.: A new method to determine Ångström's turbidity coefficient: Its application for Valencia, Solar Energy, 54, 219-226, 1995.

Power, H. C.: Estimating atmospheric turbidity from climate data, Atmos. Env., 35, 125-134, 2001.

Sinha, S., Kumar, S. and Kumar, N.: Energy conservation in highrise buildings: changes in air conditioning load induced by vertical temperature and humidity profile in Delhi, Ener. Conv. Management, 39, 437-440, 1998.

Shüepp, W.: Die Bestimmung der Komponenten der atmosphärischen Trübung aus Aktinometer Messungen, Arch. Met. Geoph. Biokl. B, 1, 257-346, 1949.

Unsworth, M. H. and Monteith, J. L.: Aerosol and solar radiation in Britain, Quart. J. Roy. Meteor. Soc., 98, 778-797, 1972.

Van Heuklon, T. K.: Estimating atmospheric ozone for solar radiation models, Solar Energy, 22, 63-68, 1979.

Viswanadham, Y.: The relationship between total precipitable water and surface dew point, J. Appl. Meteo., 20, 3-8, 1981.

Wright, J., Perez, R. and Michalsky, J. J.: Luminous efficacy of direct irradiance: variations with insolation and moisture conditions, Solar Energy, 42, 387-394, 1989. 